\title{
Investigation of the Pseudopotential Stuttgart/Dresden in the
}

\section{G3(MP2,CSSD, rel) Theory for Compounds Containg Transition Elements}

\author{
Cleuton S. Silva \& Rogério Custodio
}

\section{Introduction}

The Gaussian Theory ${ }^{1,2}$ has been developed over the last decades with the goal of approaching exact molecular energies using a set of calculations based primarily on $\mathrm{ab}$ initio molecular orbital theory with different levels of accurancy and basis set.

DeYonker et al. ${ }^{3}$ test set comprising 17 enthalpies of formation for transition metal compounds for testing their method referred to as the correlation consistent composite approach (ccCA). On this test set of 17 enthalpies, their ccCA method has a mean absolute deviation (MAD) of $5.6 \mathrm{kcal} / \mathrm{mol}$, which is just under twice the average experimental uncertainty of 3.1 for this set of molecules.

Mayhall et al. ${ }^{4}$ Collected a test set comprising 20 enthalpies of formation for transition metal compounds for testing their method referred to as the G3(MP2,CCSD,rel). On this test set of 20 enthalpies, their G3(MP2,CCSD,rel) method has a mean absolute deviation (MAD) of $4.58 \mathrm{kcal} / \mathrm{mol}$, which is just under twice the average experimental uncertainty of 1.5 Kcal/Mol.

Recently, the use of the CEP pseudopotential (Compact Effective Potential) along with the G3 theory ${ }^{5}$ proved to be possible preserving a high level of accuracy and providing a considerable gain in the CPU time. The objective of this work is to adapt the stuttgart/dresden pseudopotential in the G3(MP2,CCSD,rel).

\section{Methods}

The G3(MP2,CCSD,rel). composite model combines high-level correlation/moderate basis set calculations with lower level correlation/larger basis set calculations to approximate the results of a more expensive calculation. The composite energy is obtained from results using $\operatorname{CCSD}(\mathrm{T})$, MP2, and DKH calculations with progressively larger basis sets, and including first-order spin-orbit corrections for atoms and molecules (SO), zero-point energy corrections (ZPE), and an empirical higher level correction (HLC) that depends on the number of paired and unpaired electrons.

All steps of the original G3(MP2,CCSD,rel) theories were used and adapted to include the stuttgart/dresden pseudopotential G3(MP2,CCSD,rel,SDD) The scalar relativistic corrections to the energies are obtained from DKH-CCSD(T)/6-31G(d) single-point energy calculations using a second-order Douglas-Kroll-Hess (DKH) scalar relativistic Hamiltonian:

$$
\begin{aligned}
& \mathrm{Eo}[\mathrm{G} 3(\mathrm{MP} 2, \mathrm{CCSD}, \mathrm{rel})])=\mathrm{CCSD}(\mathrm{T}) / 6-31 \mathrm{G}(\mathrm{d}) \\
& +\Delta \mathrm{E}(\mathrm{MP} 2)+\Delta \mathrm{E}(\mathrm{rel})+\Delta \mathrm{E}(\mathrm{SO})+\mathrm{E}(\mathrm{HLC})+\mathrm{E}(\mathrm{ZPE})
\end{aligned}
$$

And

$\Delta \mathrm{E}(\mathrm{MP} 2))=\mathrm{E}[\mathrm{MP} 2 / \mathrm{G} 3 \mathrm{MP} 2 \mathrm{LargeXP}]-$

$\mathrm{E}[\mathrm{MP} 2 / 6-31 \mathrm{G}(\mathrm{d})]$

$\Delta \mathrm{E}(\mathrm{rel}))=\mathrm{E}[\mathrm{DKH}-\mathrm{CCSD}(\mathrm{T}) / 6-31 \mathrm{G}(\mathrm{d})]-$ 


\section{Results and Discussion}

Table 1 contains the total energies of the atoms $\mathrm{Sc}-\mathrm{Zn}$ from the G3(MP2,CCSD,rel) and G3(MP2,CCSD, rel,SDD) methods. The deviations for all 20 molecules are given in this table with the mean absolute deviation at the bottom of the table. All of the deviations are in kilocalories per mole and calculated as experiment minus theory.

The MAD of $4.58 \mathrm{kcal} / \mathrm{mol}$ for G3(MP2,CCSD,rel) with a maximum deviation of $9.37 \mathrm{kcal} / \mathrm{mol}$. The MAD of $4.39 \mathrm{kcal} / \mathrm{mol}$ for G3(MP2,CCSD,rel,SDD) with a maximum deviation of $-16.07 \mathrm{kcal} / \mathrm{mol}$. Most notable is the result for $\mathrm{VO}$, where G3(MP2,CCSD,rel,SDD) differs by $-16.07 \mathrm{kcal} / \mathrm{mol}$ from experiment while G3(MP2,CCSD,rel) differs by only $-1.97 \mathrm{kcal} / \mathrm{mol}$. If $\mathrm{VO}$ is excluded, the G3(MP2,CCSD,rel,SDD) mean absolute deviation is about the same as for G3(MP2,CCSD,rel).

Table 1: Comparison of G3(MP2,CCSD,rel) and 3(MP2,CCSD,rel,SDD) Methods for Calculation of $\Delta \mathrm{Hf}(298 \mathrm{~K})$ for a Test Set of 20 Molecules

\begin{tabular}{|c|c|c|c|}
\hline Molecule & Experiment & $\begin{array}{c}\text { G3(MP2, } \\
\text { CCSD, rel) }\end{array}$ & $\begin{array}{c}\text { G3(MP2, } \\
\text { CCSD, rel, } \\
\text { SDD) }\end{array}$ \\
\hline $\mathrm{ScO}$ & $-13.0 \pm 2.2$ & -2.4 & -6.02 \\
\hline $\mathrm{ScCl} 3$ & $-160,5 \pm 2.1$ & 5.97 & 0.37 \\
\hline $\mathrm{TiO}$ & $-13.7 \pm 2.2$ & 0.68 & -4.89 \\
\hline $\mathrm{TiF} 4$ & $-370.8 \pm 1$ & 5.48 & 0.24 \\
\hline $\mathrm{VO}$ & $-31.8 \pm 2$ & -1.97 & -16.07 \\
\hline $\mathrm{CrCl}$ & $-31.0 \pm 0.6$ & 1.13 & 1.87 \\
\hline $\mathrm{CrO} 3$ & $-77.3 \pm 1$ & 9.12 & 2.67 \\
\hline $\mathrm{MnCl}$ & $15,8 \pm 1.6$ & 9.37 & 9.21 \\
\hline $\mathrm{MnS}$ & $63.31 \pm 2$ & 1.5 & -3.10 \\
\hline $\mathrm{FeCl}$ & $49.5 \pm 1.6$ & 8.95 & 0.46 \\
\hline $\mathrm{FeCl} 2$ & $-32.8 \pm 1$ & 7.71 & -1.66 \\
\hline $\mathrm{FeCl} 3$ & $-60.5 \pm 1.2$ & 9.43 & 5.45 \\
\hline $\mathrm{CoCl} 2$ & $-22.6 \pm 1$ & 5.56 & -0.63 \\
\hline $\mathrm{CoCl} 3$ & $-39.1 \pm 2.5$ & 2.94 & -5.29 \\
\hline $\mathrm{NiCl} 2$ & $-17.4 \pm 1$ & 5.35 & -0.17 \\
\hline $\mathrm{NiF} 2$ & $-77.8 \pm 1.1$ & 8.9 & 7.73 \\
\hline $\mathrm{CuH}$ & $65.9 \pm 2$ & -0.53 & -10.32 \\
\hline $\mathrm{CuCl}$ & $19.3 \pm 2$ & 0.83 & 11.50 \\
\hline $\mathrm{ZnH}$ & $62.9 \pm 0.5$ & 0.31 & 0.14 \\
\hline $\mathrm{Zn}(\mathrm{CH} 3) 2$ & $12.86 \pm 2$ & 3.52 & 0.04 \\
\hline $\mathrm{MAD}$ & & 4.58 & 4.39 \\
\hline
\end{tabular}

The average uncertainty for the 20 molecule transition metal set is $1.5 \mathrm{kcal} / \mathrm{mol}$, so the MAD is less than twice the experimental uncertainty. In addition, some experimental atomic enthalpies of formation, such as for $\mathrm{Ti}, \mathrm{V}$, and $\mathrm{Ni}$, have uncertainties of $2-4 \mathrm{kcal} / \mathrm{mol}$. These are used in the calculation of the molecular enthalpies and may introduce uncertainties in the theoretical values. In a paper, Mayhall et al. G4(rel) the MAD of $4.07 \mathrm{kcal} / \mathrm{mol}$ with a maximum deviation of $21,31 \mathrm{kcal} / \mathrm{mol}$. The MAD of $4.39 \mathrm{kcal} / \mathrm{mol}$ for G3(MP2,CCSD, rel,SDD) with a maximum deviation of $-16.07 \mathrm{kcal} / \mathrm{mol}$.

\section{Conclusions}

The G3(MP2,CCSD,rel,SDD) method, which includes scalar relativistic effects, has a mean absolute deviation of $4,39 \mathrm{kcal} / \mathrm{mol}$ and a maximum deviation of $-16.07 \mathrm{kcal} / \mathrm{mol}$ for the test set of 20 enthalpies. Since the 20 enthalpies have an average experimental uncertainty of $1.5 \mathrm{kcal} / \mathrm{mol}$, these results indicate that the G4(MP2,rel) method performs well for transition metals. The G3(MP2,CCSD,rel,SDD) failure stuttgart/dresden pseudopotential, which is particularly large for one molecule, VO.

\section{Acknowledgments}

The authors are grateful for the support given from the FAPEAM, CAPES, CNPQ and FAPESP e FAIPEX(UNICAMP).

\section{References}

1. L. Curtiss, R. Raghavachari, P. Radfern, V. Rassolov. J. Chem. Phys.,109, 7764, (1998).

2. L. Curtiss, R. Raghavachari, P. Radfern, J. Chem. Phys.,126, 084108, (2007).

3. J. DeYonker, K. Peterson, G. Steyl, A. Wilson, T. Cundari, J. Phys. Chem. A, 111 , 11269, (2009).

4. N. Mayhall, R. Raghavachari, P. Radfern, L. Curtiss. J. Phys. Chem. A, 113 , 5170, (2009).

5. D. Pereira, A. Ramos, N. Morgon, R. Custodio J. Chem. Phys. 135, 034106,(2011).

\section{Cleuton S. Silva ${ }^{a, b},^{*} \&$ Rogério Custodio ${ }^{b}$}

${ }^{a}$ Institute of Scinces Exact and technology, Federal University Of Amazonas, Cep: 69077-000, Itacoatiara-AM;

${ }^{b}$ Department Of Physical Chemistry, Institute of Chemistry, State University of Campinas, Cep: 13083-872, Campinas-SP;

*E-mail: cleutonsouza@yahoo.com.br; 